\title{
Bone material strength index as measured by impact microindentation is low in patients with fractures irrespective of fracture site
}

\author{
F. Malgo ${ }^{1}$ (D) - N.A.T. Hamdy ${ }^{1}$ - S.E. Papapoulos ${ }^{1}$ - N.M. Appelman-Dijkstra ${ }^{1}$
}

Received: 19 October 2016 / Accepted: 12 April 2017 /Published online: 2 May 2017

(C) The Author(s) 2017. This article is an open access publication

\begin{abstract}
Summary We evaluated the relationship between bone material strength index (BMSi) and fragility fractures, including vertebral fractures. Our data showed that BMSi is low in all fracture patients with low bone mass, independently of whether patients sustained a vertebral or a non-vertebral fracture. Introduction Impact microindentation (IMI) is a new technique for the measurement of tissue level properties of cortical bone in vivo. Previous studies showed an association between BMSi and non-vertebral fractures, but an association with vertebral fractures is still being debated. The objective of this paper was to evaluate the relationship between BMSi and different types of fragility fractures, including vertebral fractures.

Methods In this cross-sectional study, we measured BMSi in patients of both sexes with different types of fragility fractures and low bone mass with the IMI method using the Osteoprobe ${ }^{\circledR}$. Vertebral fractures were diagnosed and graded on lateral spine radiographs.

Results A total of 132 patients were included in the study, of whom 101 patients (65 women) had sustained a low energy fracture and 31 (mean age $57.7 \pm 9.9$ years) had no history or radiological evidence for a fracture. Of the fracture patients, 53 (mean age $62.8 \pm 8.3$ years) had only non-vertebral fractures $(\mathrm{VF}-/ \mathrm{Fx}+), 34$ (mean age $62.8 \pm 9.9$ years) had vertebral and non-vertebral fractures $(\mathrm{VF}+/ \mathrm{Fx}+)$, and 14 (mean age $64.7 \pm 9.3$ years $)$ had only vertebral fractures $\left(\mathrm{VF}+/ \mathrm{Fx}^{-}\right)$. $\mathrm{BMSi}$ values, adjusted for age and BMD, were similar for
\end{abstract}

N.M. Appelman-Dijkstra

N.M.Appelman-Dijkstra@lumc.nl

1 Center for Bone Quality and Department of Medicine, Division Endocrinology, Leiden University Medical Center, P.O. Box 9600, 2300, RC Leiden, The Netherlands all three groups of fracture patients $(78.9 \pm 0.7,78.3 \pm 0.9$, and $78.4 \pm 1.4$, respectively; $p=0.866$ ). BMSi values were not associated with number or severity of vertebral fractures. Conclusion Our data demonstrate that BMSi is low in fracture patients with low bone mass, irrespective of whether they sustained a vertebral fracture or a non-vertebral fracture.

Keywords Fragility fracture · Impact microindentation · Reference point indentation $\cdot$ Vertebral fracture

\section{Introduction}

Reference point indentation (RPI) is a technique to measure cortical bone indentation properties in vivo and to potentially assess bone mechanical properties. Currently available RPI devices use two different methods to assess cortical bone resistance to indentation namely cyclic microindentation (CMI, Biodent) and impact microindentation with an easier to use hand-held indenter (IMI, OsteoProbe), the latter being specifically designed for in vivo use in humans and large animals [1-3]. The principles, similarities, and differences as well as results of clinical application of the two devices were recently reviewed [4-6]. In a direct comparison of the two methods in cadaveric human tibiae, Karim and colleagues reported that results of measurements are weakly related indicating that each device reflects different aspects of cortical bone indentation properties [7]. Although the exact properties of bone measured in vivo by microindentation need to be determined, clinical studies with both devices demonstrated that the method could differentiate patient groups with increased fracture risk from control groups independently of bone mineral density (BMD) values suggesting that the method measures aspects of bone fragility not captured by BMD. 
Initial application of CMI in humans showed that postmenopausal women with osteoporotic fractures (hip or vertebra) or those with atypical femoral fractures had greater indentation distances compared with controls, which were poorly related with hip BMD $[2,8]$. Clinical studies with IMI demonstrated that the measured parameter bone material strength index (BMSi) was significantly lower in postmenopausal women with type 2 diabetes mellitus compared with healthy controls in the presence of similar BMD values [9], and patients treated with glucocorticoids showed significant deterioration of BMSi within 7 weeks of starting treatment, before any changes in BMD [10]. Our group also showed that despite similar BMD values, BMSi values were lower in patients with fragility fractures compared with those without fractures [11].

The impact microindentation technique has recently been used to examine the association between BMSi and vertebral fractures, but results are conflicting. In a population-based cohort of 211 older women with or without fractures, including 58 women with vertebral fractures, there was no association between BMSi values and prevalent vertebral fractures [12]. In contrast, a preliminary communication of a study in 101 postmenopausal women (30 with vertebral fractures) reported lower BMSi values in patients with fractures than in healthy controls and a significant inverse relationship between BMSi and severity of vertebral fractures [13].

The question raised by these studies is whether BMSi as measured by IMI provides information on just cortical bone fragility or on overall bone fragility. To address this question, we expanded our previously reported cohort to specifically examine the association between BMSi and different types of fragility fractures, in particular those of the vertebrae.

\section{Patients and methods}

This was a cross-sectional study that evaluated BMSi in men and women attending the outpatient clinic of the Center for Bone Quality of the Leiden University Medical Center (LUMC). The patients described in the current study include those of our previous report of the comparison of BMSi between patients with fragility fractures and those without fractures [11]. The study design, inclusion and exclusion criteria, and methodology used were previously described [11] and are summarized below. The Medical Ethics Committee of the LUMC approved the study and informed consent was obtained from all patients.

Sequentially invited patients aged between 40 and 85 years with low bone mass (osteopenia or osteoporosis), and no secondary osteoporosis or other metabolic bone disease were invited to participate in the study. Other exclusion criteria included serum $25-\mathrm{OH}$ vitamin D concentrations $\leq 25 \mathrm{nmol} /$ 1, current use of glucocorticoids, aromatase inhibitors, androgen deprivation therapy, or chemotherapy or ever use of bone- acting agents such as bisphosphonates or denosumab. Fragility fractures were defined as any low-energy fracture, excluding those of hands, feet, and skull. FRAX 10-year probabilities for a major osteoporotic fracture and a hip fracture, with and without femoral neck BMD, were calculated using the FRAX algorithm [14]. Blood was collected for standard laboratory investigations including calcium, creatinine, parathyroid hormone, and 25-OH vitamin D. BMD was measured by DXA (Hologic QDR 4500), and conventional lateral radiographs of the thoracic and lumbar spine were obtained. Vertebral fractures were identified and graded according to the semi-quantitative method of Genant by two of the authors (F.M. and N.A.-D.) [15]. Kappa was 0.85 .

BMSi was measured in all patients by impact microindentation (IMI) $[3,5]$ on the midshaft of the right tibia using a hand-held microindenter (OsteoProbe ${ }^{\circledR}$ RUO, Active Life Scientific, CA, USA) by a single operator [11]. The patient is placed in a decubitus supine position with the tibia in external rotation to orient the flat surface of the medial tibia diaphysis in a horizontal position. The measurement site is defined as the mean distance between the distal apex of the patella and medial malleolus. Following disinfection of the area and local anesthesia of the skin and periosteum with Lidocaine $1 \%$, the test probe is gently inserted in the skin until the bone surface is reached. The operator ensures that the test probe is placed perpendicularly to the bone surface and classifies the measurements as "well performed," "adequate," or "poorly performed" after the indentation and before checking the computer display of the result. "Poorly performed" measurements are usually due either to slipping of the test probe or to moving of the subject's leg and are discarded. After five adequate measurements, as recommended [5], five additional measurements are performed on a polymethylmethacrylate (PMMA) calibration phantom. BMSi is calculated as 100 times the harmonic mean of the indentation distance increase from impact into the PMMA material divided by the average indentation distance increase from impact into bone. As the probe indents the surface of the cortical bone of the tibia, it induces a microfracture. The more easily this occurs, the deeper the probe indents the bone, and thus, the lower the BMSi is [3].

In 10 subjects, the measurement was repeated in the same leg at sites $2 \mathrm{~cm}$ apart; mean (SD) of the two measurements was $75.9 \pm 5.7$ and $76.6 \pm 4.9$, respectively. The intra-observer coefficient of variation $(\mathrm{CV})$ was $2.2 \%$.

\section{Statistical analysis}

All data are expressed as mean \pm SD unless otherwise stated. Between-group differences in baseline characteristics were assessed by Student's $t$ test, ANOVA, and Chi square test or a Mann-Whitney $U$ test or Kruskall-Wallis test for non- 
normally distributed variables. Post hoc analyses using Bonferroni were performed to adjust for multiple comparisons if required, and non-parametric post hoc analyses using Kruskall-Wallis were performed to compare BMSi values between the three fracture groups and non-fracture controls. Pearson's or Spearman's correlations were used to assess correlations between patients' parameters and BMSi. ANOVA with BMSi as outcome variable, adjusted for age, was used to compare BMSi values between patients with fractures and those without fractures. The relationship between BMSi and the severity of vertebral fractures was assessed by a linear multiple regression model adjusted for age and femoral neck BMD. A probability level of random difference of 0.05 was considered significant. The SPSS software for Windows (Version 23; SPSS Inc., Chicago, IL, USA) was used for statistical analysis of results.

\section{Results}

One hundred and thirty-two patients (64\% women), 101 of whom had sustained at least one fragility fracture, consented to take part in the study and underwent impact microindentation, a median of 3.3 months after their most recent fracture, Table 1. Mean age of the whole group was $61.8 \pm 9.4$ years, 76 patients (58\%) had osteopenia, and 56 $(42 \%)$ osteoporosis. Consistent with our previous findings, in this larger cohort, we found that BMSi was inversely and significantly related with age $(r=-0.485, p<0.001)$ and with FRAX 10-year probability calculated with and without femoral neck BMD (Spearman's $r=-0.313, p<0.001$, and Spearman's $r=-0.356, p<0.001$, respectively). There was no correlation between BMSi with any other patient characteristic, laboratory, or BMD value. There was no difference in BMSi values between women and men $(79.7 \pm 0.6$ vs 80.0 $0.8 ; p=0.789)$. In the whole cohort of subjects with low bone

Table 1 Demographic characteristics of 132 patients with low bone mass

\begin{tabular}{llll}
\hline & Fracture $(n=101)$ & No fracture $(n=31)$ & $p$ value \\
\hline Age $($ years $)$ & $63.1 \pm 8.9$ & $57.5 \pm 9.9$ & 0.004 \\
Male/female & $36 / 65$ & $11 / 20$ & 0.987 \\
BMI $\left(\mathrm{kg} / \mathrm{m}^{2}\right)$ & $24.6 \pm 3.5$ & $25.1 \pm 4.7$ & 0.475 \\
PTH $(\mathrm{pmol} / \mathrm{L})$ & $3.6 \pm 1.8$ & $3.4 \pm 1.4$ & 0.618 \\
Calcium $(\mathrm{mmol} / \mathrm{L})$ & $2.41 \pm 0.09$ & $2.40 \pm 0.10$ & 0.784 \\
25-OH D $(\mathrm{nmol} / \mathrm{L})$ & $66.2 \pm 27.1$ & $78.1 \pm 30.0$ & 0.080 \\
Creatinine $(\mu \mathrm{mol} / \mathrm{L})$ & $73.4 \pm 12.3$ & $76.7 \pm 15.2$ & 0.228 \\
LS BMD $\left(\mathrm{g} / \mathrm{cm}^{2}\right)$ & $0.87 \pm 0.12$ & $0.83 \pm 0.08$ & 0.090 \\
FN BMD $\left(\mathrm{g} / \mathrm{cm}^{2}\right)$ & $0.67 \pm 0.08$ & $0.68 \pm 0.07$ & 0.672 \\
\hline
\end{tabular}

$B M I$ body mass index, $P T H$ parathyroid hormone, $L S$ lumbar spine, $F N$ femoral neck, $B M D$ bone mineral density mass, patients with fractures had significantly lower ageadjusted BMSi values than those without fractures $(79.0 \pm 0.5$ vs $82.5 \pm 0.9 ; p=0.001)$.

Fifty-three patients had only non-vertebral fractures (VF $-/ \mathrm{Fx}+), 34$ had non-vertebral and vertebral fractures $(\mathrm{VF}+/$ $\mathrm{Fx}+)$, and 14 had only vertebral fractures $\left(\mathrm{VF}+/ \mathrm{Fx}^{-}\right)$, Table 2. Clinical characteristics and biochemical findings were similar among the three groups with the exception of PTH values and femoral neck BMD which were lower in the $(\mathrm{VF}-/ \mathrm{Fx}+)$ group.

To evaluate possible differences in fracture risk due to different fracture history, we analyzed the number and type of prevalent non-vertebral fractures in the two groups. Twentyfour $(71 \%)$ patients in the $(\mathrm{VF}+/ \mathrm{Fx}+)$ group and $31(59 \%)$ patients in the $(\mathrm{VF}-/ \mathrm{Fx}+)$ group had only one prevalent nonvertebral fracture $(p=0.254)$. The number of patients with hip fractures did not differ between groups (6 vs 7, respectively). Similarly, there was no difference between the two groups in the total number of prevalent non-vertebral fractures, [48/34 (1.4 per patient) vs $76 / 53$ (1.4 per patient)] or major nonvertebral fractures [34/34 (1.0 per patient) vs $45 / 53$ ( 0.8 per patient)].

\section{BMSi and vertebral fractures}

BMSi values were similar in the three fracture groups and significantly lower than those of the non-fracture control group, Fig. 1. Results remained unchanged after exclusion of patients with mild (grade 1) vertebral fractures from the analysis.

We further examined the relationship between BMSi and the number and severity of vertebral fractures as classified using Genant's grading of vertebral fractures. There were 28 patients with 1 vertebral fracture, 9 with two vertebral fractures, and 11 had 3 or more vertebral fractures. There was no difference in BMSi in patients with 1,2 , or $\geq 3$ vertebral fractures $(78.6 \pm 0.9,76.8 \pm 1.6,79.0 \pm 1.4 ; p=0.555)$.

Eighteen patients had a grade 1 vertebral fracture as their highest graded fracture, 20 had grade 2, and 10 had grade 3 . There was no relationship between BMSi values and the severity of vertebral fractures $(\beta=0.826 ; p=0.375)$.

\section{Discussion}

The present study confirms our previous results demonstrating that BMSi is lower in patients who had sustained one or more fragility fractures compared to patients who never sustained a fracture, independently of BMD measurements. It also demonstrates that vertebral fractures are associated with low BMSi values, which are not further negatively affected by the additional presence of non-vertebral fractures, including hip fractures. Taken together, these findings suggest that BMSi as 
Table 2 Demographic characteristics of 101 patients with low bone mass and fragility fractures

\begin{tabular}{lllll}
\hline & $\mathrm{VF}+\mathrm{Fx}-(n=14)$ & $\mathrm{VF}+\mathrm{Fx}+(n=34)$ & $\mathrm{VF}-/ \mathrm{Fx}+(n=53)$ & $p$ value \\
\hline Age $($ years $)$ & $64.7 \pm 9.3$ & $62.8 \pm 9.9$ & $62.8 \pm 8.3$ & 0.761 \\
Male/female & $8 / 6$ & $14 / 20$ & $14 / 39$ & 0.073 \\
BMI $\left(\mathrm{kg} / \mathrm{m}^{2}\right)$ & $25.4 \pm 3.1$ & $24.7 \pm 3.6$ & $24.3 \pm 3.6$ & 0.574 \\
PTH $(\mathrm{pmol} / \mathrm{L})$ & $4.3 \pm 2.0$ & $4.0 \pm 1.8$ & $3.2 \pm 1.6$ & 0.021 \\
Calcium $(\mathrm{mmol} / \mathrm{L})$ & $2.39 \pm 0.10$ & $2.41 \pm 0.11$ & $2.42 \pm 0.08$ & 0.657 \\
25-OH D $(\mathrm{nmol} / \mathrm{L})$ & $64.8 \pm 24.6$ & $67.1 \pm 28.0$ & $66.0 \pm 27.6$ & 0.932 \\
Creatinine $(\mu \mathrm{mol} / \mathrm{L})$ & $79.4 \pm 10.3$ & $74.3 \pm 11.7$ & $71.2 \pm 12.8$ & 0.078 \\
LS BMD $\left(\mathrm{g} / \mathrm{cm}^{2}\right)$ & $0.86 \pm 0.11$ & $0.88 \pm 0.16$ & $0.87 \pm 0.10$ & 0.833 \\
FN BMD $\left(\mathrm{g} / \mathrm{cm}^{2}\right)$ & $0.70 \pm 0.09$ & $0.69 \pm 0.09$ & $0.65 \pm 0.07$ & $0.010^{\mathrm{a}}$ \\
\hline
\end{tabular}

$V F+/ F x$ - only vertebral fractures, $V F+/ F x+$ vertebral fractures and non-vertebral fractures, $V F-/ F x+$ only nonvertebral fractures, $B M I$ body mass index, $P T H$ parathyroid hormone, $L S$ lumbar spine, $F N$ femoral neck, $B M D$ bone mineral density

${ }^{\mathrm{a}}$ Post hoc notations FN BMD: VF+/Fx+ vs VF-/Fx+; $p=0.05$ measured by IMI on the tibia is associated with increased bone fragility at all relevant skeletal sites.

Our results are in keeping with those of Duarte Sosa et al. who reported in a preliminary communication that postmenopausal women with fractures, including those of the spine, had significantly lower BMSi values than controls [13]. Our data are at odds, however, with those of Rudang et al. who reported no difference in BMSi values between women with and without fractures, and no association between BMSi and vertebral fractures [12]. Various reasons may be responsible for the discrepancy in results between the latter study and ours, all related to major differences in design and methodology. Firstly, Rudang and colleagues studied elderly women, aged between 75 and 80 years, who were recruited from a population cohort while we included a clinically based cohort of men and women aged between 40 and 85 years in whom we demonstrated a significant relationship between age and BMSi values. Secondly, broad inclusion criteria were used in this study compared to the strict selection criteria for inclusion in our study, an important prerequisite for studies using new methodologies. Thirdly, in our study, the presence of fractures was radiologically confirmed in all patients compared to information about non-vertebral fractures obtained by questionnaire and not confirmed by review of medical records or radiographs. Finally, subjects with traumatic fractures who were specifically excluded in our study were included although it is not yet clear whether such fractures are associated with altered bone composition. Moreover, in our study, BMSi measurements were performed by a single operator compared to 4 different operators in the study of Rudang and colleagues leading to the need to adjust their data because of the significant differences in the results obtained.

It should be also noted that differences in BMSi values were observed in a study of 42 Norwegian and 46 Spanish women suggesting possible geographical variations in BMSi [16]. These differences in BMSi between countries suggest that, similar to FRAX, normative values for BMSi should perhaps be developed for different countries to minimize the implications of these differences in the interpretation of BMSi results.

Our study has strengths as well as limitations. Of the strengths of the study is the consecutive inclusion of men and women aged between 40 and 85 years with low bone mass attending our outpatient clinic. Although this is a main strength in our group of patients with fractures, it may be also perceived as a limitation of our patient control group because BMD measurements were performed at the discretion of the patients' physician. A further strength of our study is that patients who were currently using or had used bone-

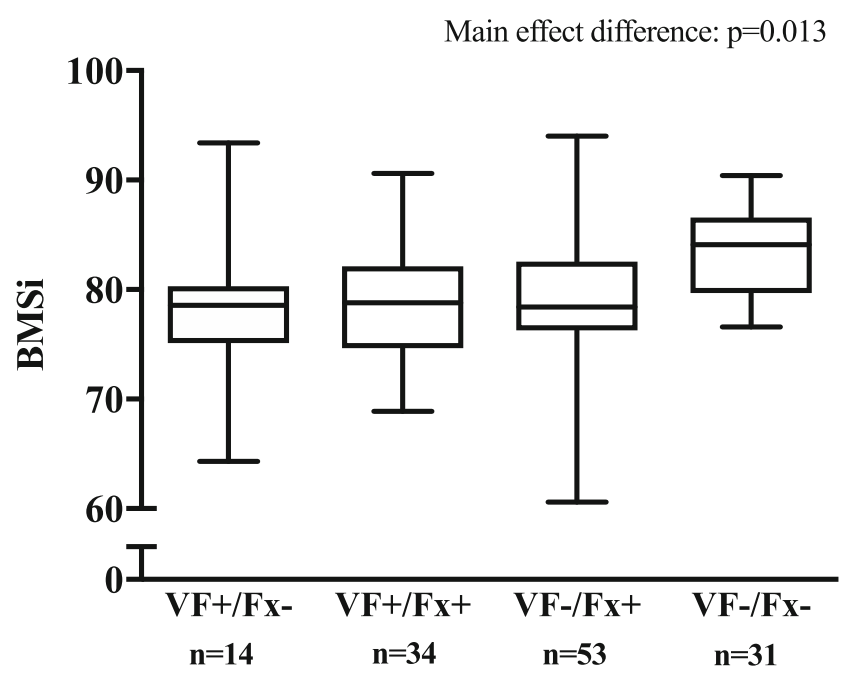

Fig. 1 Bone material strength index (BMSi) in patients with only vertebral fractures $\left(\mathrm{VF}+/ \mathrm{Fx}^{-}\right)$, vertebral fractures and non-vertebral fractures $(\mathrm{VF}+/ \mathrm{Fx}+)$, only non-vertebral fractures $(\mathrm{VF}-/ \mathrm{Fx}+)$, and in control patients $\left(\mathrm{VF}-/ \mathrm{Fx}^{-}\right)$. Data are shown as box whisker plots. Boxes indicate median and interquantile range. Bars indicate minimum and maximum values. Main effect difference: $F=3.74 ; p=0.013$. Post hoc notations: $\mathrm{VF}+/ \mathrm{Fx}-\mathrm{Vs} \mathrm{VF}-/ \mathrm{Fx}-; p=0.004, \mathrm{VF}+/ \mathrm{Fx}+\mathrm{Vs} \mathrm{VF}-/ \mathrm{Fx}-;$ $p=0.001, \mathrm{VF}-/ \mathrm{Fx}+\mathrm{Vs} \mathrm{VF}-/ \mathrm{Fx}^{-} ; p<0.001$ 
modifying agents were excluded, although this might also have resulted in the exclusion of patient known to have a high fracture risk. Of the limitations of our study are its crosssectional design and the limited sample size after stratification for fracture type.

In conclusion, we show that BMSi measured by IMI is low in patients with fragility fractures regardless of whether this is a vertebral or a non-vertebral fracture. These data suggest that BMSi may reflect general bone fragility although this remains to be established in prospective studies.

Acknowledgements We thank S. Tsonaka, PhD Department of Medical Statistics and Bioinformatics, Leiden University Medical Center for her help in the statistical analysis of the results.

\section{Compliance with ethical standards}

Conflicts of interest Frank Malgo, Neveen A.T. Hamdy, and Natasha M. Appelman-Dijkstra declare that they have no conflict of interest. Socrates E. Papapoulos is an unpaid member of the Scientific Board of Active Life Scientific, manufacturer of OsteoProbe.

Open Access This article is distributed under the terms of the Creative Commons Attribution-NonCommercial 4.0 International License (http:// creativecommons.org/licenses/by-nc/4.0/), which permits any noncommercial use, distribution, and reproduction in any medium, provided you give appropriate credit to the original author(s) and the source, provide a link to the Creative Commons license, and indicate if changes were made.

\section{References}

1. Hansma P, Turner P, Drake B, Yurtsev E, Proctor A, Mathews P, Lelujian J, Randall C, Adams J, Jungmann R, Garza-de-Leon F, Fantner G, Mkrtchyan H, Pontin M, Weaver A, Brown MB, Sahar N, Rossello R, Kohn D (2008) The bone diagnostic instrument II: indentation distance increase. Rev Sci Instrum 79:064303

2. Diez-Perez A, Guerri R, Nogues X, Caceres E, Pena MJ, Mellibovsky L, Randall C, Bridges D, Weaver JC, Proctor A, Brimer D, Koester KJ, Ritchie RO, Hansma PK (2010) Microindentation for in vivo measurement of bone tissue mechanical properties in humans. J Bone Miner Res 25:1877-1885

3. Bridges D, Randall C, Hansma PK (2012) A new device for performing reference point indentation without a reference probe. Rev Sci Instrum 83:044301
4. Allen MR, McNerny EM, Organ JM, Wallace JM (2015) True gold or pyrite: a review of reference point indentation for assessing bone mechanical properties in vivo. J Bone Miner Res 30:1539-1550

5. Diez-Perez A, Bouxsein ML, Eriksen EF, Khosla S, Nyman JS, Papapoulos S, Tang SY (2016) Technical note: recommendations for a standard procedure to assess cortical bone at the tissue-level in vivo using impact microindentation. Bone Rep 5:181-185

6. Herrera S, Diez-Perez A (2017) Clinical experience with microindentation in vivo in humans. Bone 95:175-182

7. Karim L, Van Vliet M, Bouxsein ML (2015) Comparison of cyclic and impact-based reference point indentation measurements in human cadaveric tibia. Bone

8. Guerri-Fernandez RC, Nogues X, Quesada Gomez JM, Torres Del Pliego E, Puig L, Garcia-Giralt N, Yoskovitz G, Mellibovsky L, Hansma PK, Diez-Perez A (2013) Microindentation for in vivo measurement of bone tissue material properties in atypical femoral fracture patients and controls. J Bone Miner Res 28:162-168

9. Farr JN, Drake MT, Amin S, Melton LJ III, McCready LK, Khosla S (2014) In vivo assessment of bone quality in postmenopausal women with type 2 diabetes. J Bone Miner Res 29:787-795

10. Mellibovsky L, Prieto-Alhambra D, Mellibovsky F, GuerriFernandez R, Nogues X, Randall C, Hansma PK, Diez-Perez A (2015) Bone tissue properties measurement by reference point indentation in glucocorticoid-induced osteoporosis. J Bone Miner Res 30:1651-1656

11. Malgo F, Hamdy NA, Papapoulos SE, Appelman-Dijkstra NM (2015) Bone material strength as measured by microindentation in vivo is decreased in patients with fragility fractures independently of bone mineral density. J Clin Endocrinol Metab 100:20392045

12. Rudang R, Zoulakis M, Sundh D, Brisby H, Diez-Perez A, Johansson L, Mellstrom D, Darelid A, Lorentzon M (2016) Bone material strength is associated with areal BMD but not with prevalent fractures in older women. Osteoporos Int 27:1585-1592

13. Duarte Sosa D, Eriksen EF (2015) Bone material properties are an independent determinant of fracture risk and vertebral fracture severity in osteoporosis. ECTS-IBMS Abstracts P29

14. Lalmohamed A, Welsing PM, Lems WF, Jacobs JW, Kanis JA, Johansson H, De Boer A, De Vries F (2012) Calibration of FRAX (R) 3.1 to the Dutch population with data on the epidemiology of hip fractures. Osteoporos Int 23:861-869

15. Genant HK, Wu CY, van Kuijk C, Nevitt MC (1993) Vertebral fracture assessment using a semiquantitative technique. J Bone Miner Res 8:1137-1148

16. Duarte Sosa D, Vilaplana L, Guerri R, Nogues X, Wang-Fagerland M, Diez-Perez A, Eriksen EF (2015) Are the high hip fracture rates among Norwegian women explained by impaired bone material properties? J Bone Miner Res 30:1784-1789 